\title{
Mathematics Art Music Architecture Education Culture
}

\author{
Sujan Shrestha ${ }^{1}$
}

\begin{abstract}
The international annual Bridges conference exploring Mathematical Connections in Art, Music, Architecture, Education and Culture was founded by Reza Sarhangi (1952-2016) in 1998 at a private liberal arts college in Kansas, Southwestern College. It is an annual conference, which has provided a remarkable multi-disciplinary model of collaboration between mathematics, arts and other cultural activities. The genuine efforts of many founding members of this organization provided an inspirational model throughout the past 20 years that has shaped the Bridges into one of the premier interdisciplinary conferences in the world. The conference has travelled across North America to Europe, and Asia, and hosts participants from dozens of countries around the world.
\end{abstract}

Keywords Mathematics · Art - Music · Architecture - Education - Culture

The international annual Bridges conference exploring Mathematical Connections in Art, Music, Architecture, Education and Culture was founded by Reza Sarhangi (1952-2016) in 1998 at a private liberal arts college in Kansas, Southwestern College (Reza Sarhangi memorial 2016). It is an annual conference, which has provided a remarkable multi-disciplinary model of collaboration between mathematics, arts and other cultural activities. The genuine efforts of many founding members of this organization provided an inspirational model throughout the past 20 years that has shaped Bridges into one of the premier interdisciplinary conferences in the world. The conference has travelled across North America to

Sujan Shrestha

sshrestha@ubalt.edu

1 Science, Information Arts and Technologies, University of Baltimore, 1420 N. Charles Street, Baltimore, MD, USA 
Europe, and Asia, and hosts participants from dozens of countries around the world. Learn more about the origins and the history of the Bridges organization in the article by Kristóf Fenyvesi (2016).

Each year, the conference hosts a series of events including formal papers' presentations, an exhibition of mathematical visual art (Fig. 1), hands-on workshop sessions given by scholars in their respective fields, mathematically inspired music, theater, and poetry presentations, and a short film festival. Every Bridges conference has a dedicated Family Day, where it opens its doors to the public and families in the community. Kids and adults of all ages experience the art exhibition as well as the synthesis of math, art and science through workshops, games, short movies, and other activities.

In 2017, the Bridges conference was held at the University of Waterloo in Waterloo, Ontario, Canada on July 27-31. In its 20th year, Bridges Waterloo 2017 marked the third time in Canada, after the two other conferences held in 2005 and 2009 in Banff, Alberta. Generously hosted by the Faculty of Mathematics and supported by the City of Waterloo, the Mussagetes Fund and the Fields Institute, Canada, the Bridges 2017 conference also celebrated the 50th anniversary of the School of Computer Science and of the faculty of Mathematics. The conference also coincided with the 60th anniversary of the University of Waterloo. Anna Beard, Brittany Ottewill, Craig Kaplan and Amy Aldous at the University of Waterloo were monumental in providing organizational support for this successful conference.

Given the Bridges mission statement of fostering research, practice and new interest in math-art connections, Bridges Waterloo 2017 attracted over 300 delegates from over 20 countries around the world. The conference comprised 4 days of talks, workshops, and interactions with an addtional excursion day (July 31, 2017) for visitors to explore southern Ontario. Bridges 2017 was attended by a diverse group of scholars that included mathematicians, scientists, artists, educators, musicians, writers, computer scientists, sculptors, architects, dancers, weavers, filmmakers, K-12 educators and students. Many individuals from the community

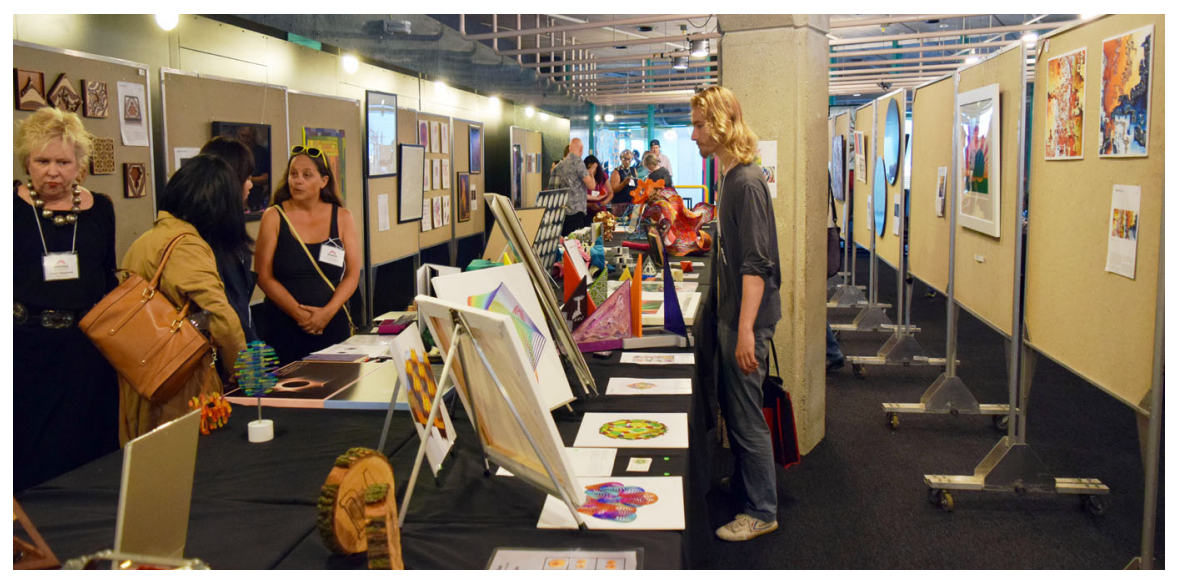

Fig. 1 The General Art Exhibition at the Bridges 2017, University of Waterloo, Ontario, Canada 
also contributed strongly to the atmosphere of collaboration, exchange of ideas and mutual inspiration.

The 2017 keynote opening talk was presented by Damian Kulash, the lead band member of the polymath rock band OK Go. Famous for its creative music videos, the band explores visual devices of illusion and anamorphosis, which are quite popular among the Bridges interdisciplinary audience. Erik Demaine, a legendary computational origamist from MIT, and also a University of Waterloo alumnus, spoke about mathematical typography (Fig. 2) in a presentation entitled "Fun with Fonts", on visualizing mathematical concepts and computational ideas.

Demaine's keynote talk also inagurated the first "Reza Sarhangi Memorial Lecture Series" highlighting the inspiring life of the beloved Bridges founder, Reza Sarhangi-his life, his passion, his dedication, his commitment to exploring Persian geometry, and his inspiring obsession with connecting mathematics, arts, and science to the global community (Fenyvesi 2016). John Edmark's fascinating

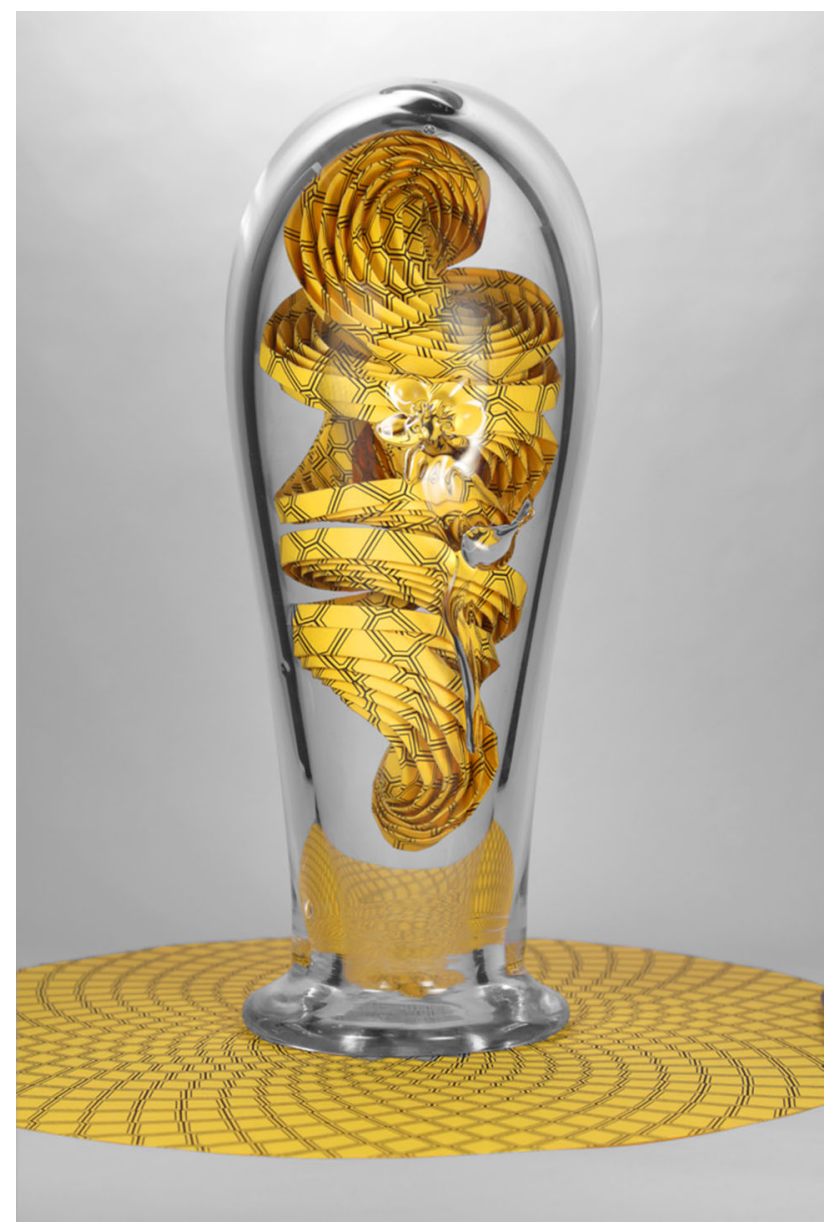

Fig. 2 "Glass Sunflower" by Erik and Martin Demaine 
presentation of his kinetic sculptures was a highlight among the 2nd day keynotes. He creates 3D printed objects designed according to the laws of phillotaxis and then rotates them and photographs them under a strobe light, so that they seem to become living, growing organisms. This results in delightful experiences of geometric motion and timeless patterns (Fig. 3). The other notable keynote speakers were Roman Verostko, Susan Goldstine, Robert Fathauer and Frank Farris, whose works have been inspirational to the Bridges audience. On July 28, 2017, Bridges also celebrated Canadian math-art research and practice in a "CanCon" day, the annual tradition of highlighting work from local mathematicians and artists. Talks honoring scholars around Waterloo and other parts of Canada examined long-exposure photography (Fig. 4), poetry, bobbin lace and architecture, inflected with mathematical thinking.

The 2017 edition of the Bridges peer-reviewed proceedings include 44 regular papers, 47 short papers, and 12 workshop papers, exploring a wide range of topics such as non-Euclidean geometry, polyhedra and higher-dimensional polytopes, tessellation, fractals and Islamic art. Other topics included are poetry, weaving, musical tuning systems, opera and 3D printing. David Swart chaired and coordinated an international Program Committee of over 50 experts who provided extensive reviews and editorial comments. Past proceedings books from 1998 to 2017 are freely available online on the Bridges website (see archive.bridgesmathart.org).

The annual Bridges Family Day, a free public event supported by the University of Waterloo, included the 12 workshop papers from the 2017 proceedings and featured hands-on math-art activities, screening of short films, workshops, games and performances (Fig. 5, 6). Organized by Kristóf Fenyvesi, the Family Day offered ranges of activities connecting mathematics and arts into a playful intriguing and magical event that can be easily deployed in the K-12 classroom. Learn more about Bridges 2017 Family Day at http://www.familyday.hu.

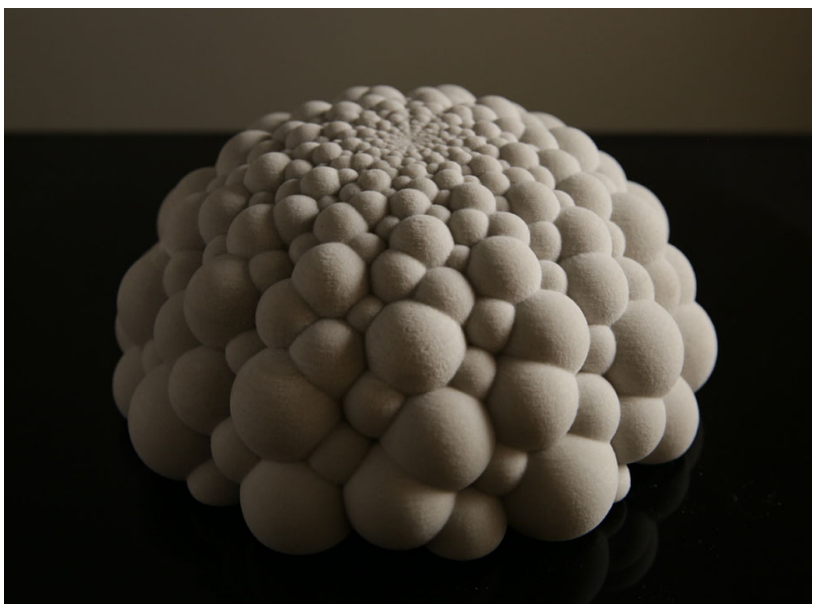

Fig. 3 "Ebullience", a bloom sculpture by John Edmark 


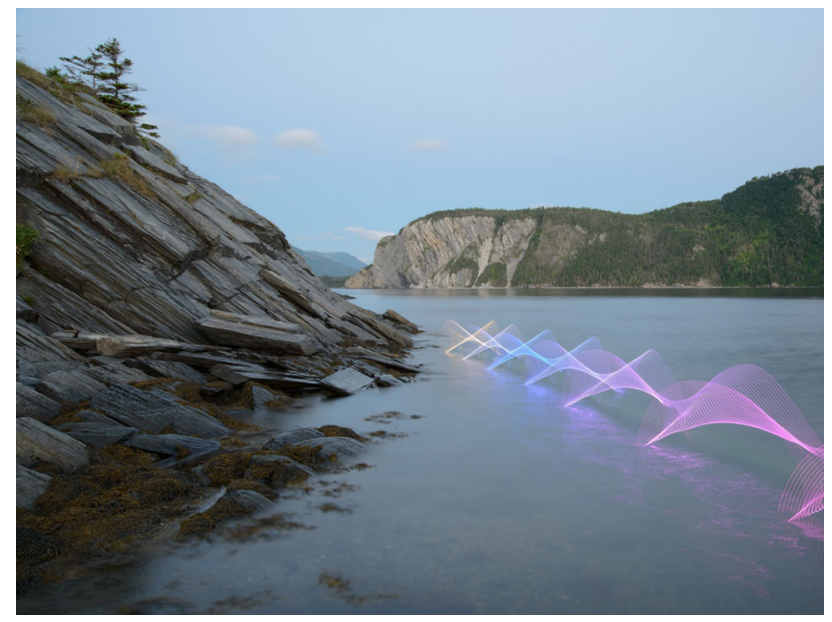

Fig. 4 "Gros Morne-Kayak I" by Stephen Orlando

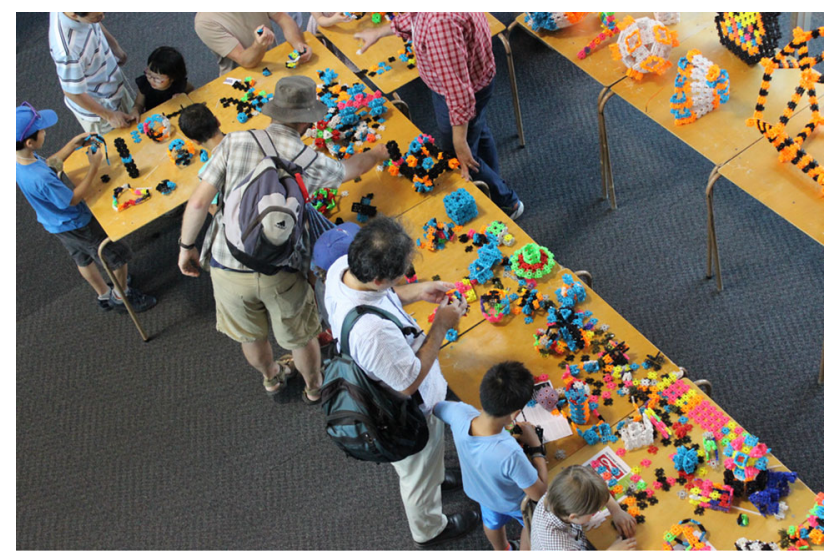

Fig. 5 Bridges 2017 Family Day, a free public annual event for kids, adults and the community

An exhibition of mathematical art has been an annual feature of Bridges since 2001. The Bridges 2017 exhibition has set a new record. Over 170 artists from all over the world participated. A wide variety of artistic media were featured in this exhibition including 2D and 3D digital prints, painting, beadwork, ceramics, wood, metal, quilting, clothing and paper folding (Figs. 7, 8, 9, 10, 11, 12, 13). Featuring both invited and contributed artworks, artists drew inspiration from the mathematics of fractals, polyhedra, non-Euclidean and four-dimensional geometry, tiling, knot theory, number theory and more (see gallery.bridgesmathart.org). At Bridges 2017, a separate exhibition was organized by the University of Waterloo Art Gallery (UWAG), highlighting mathematical artworks by five local Canadian artists.

Bridges 2017 celebrated the life and work of Magnus Wenninger (1919-2017), a mathematician and a scholar, who pioneered many models of polyhedral (Fig. 10) 


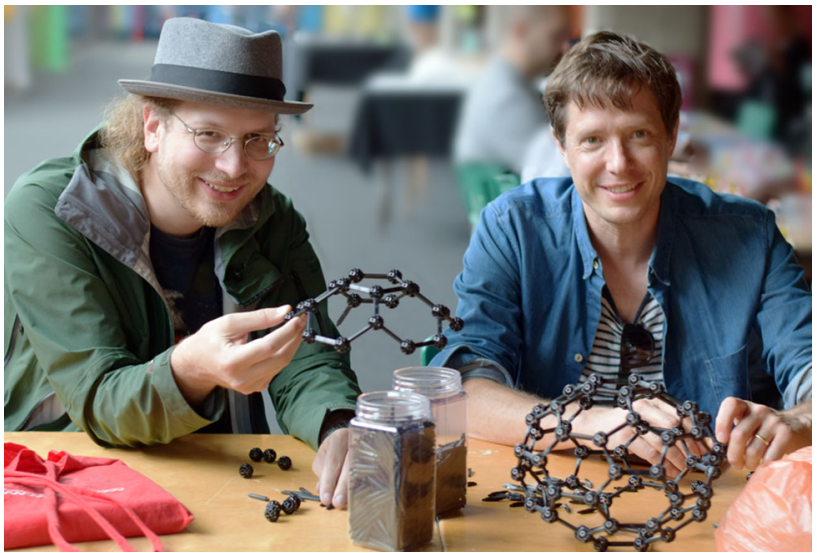

Fig. 6 Erik Demaine, MIT (Left) and Damian Kulash, OK go (Right) creating Zometool structures at Bridges 2017

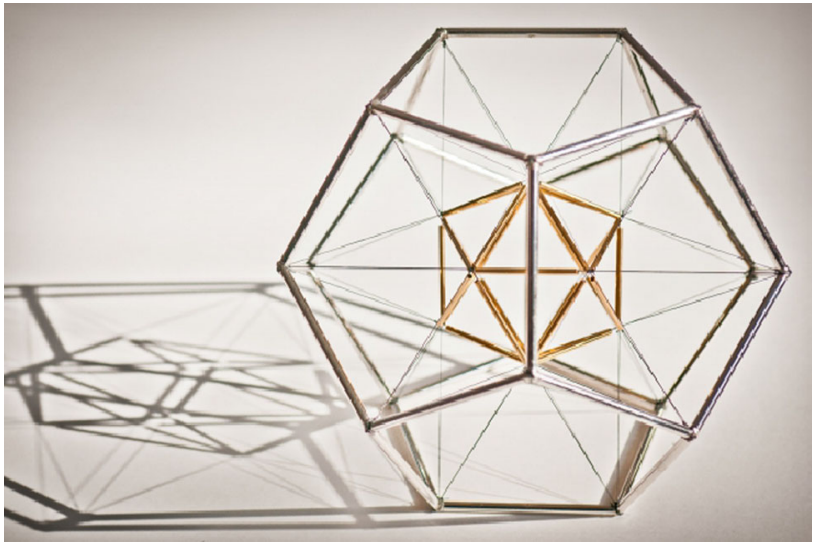

Fig. 7 "Precious Polarity" by Martin Levine, Winner of Best Use of Mathematics, Bridges 2017

and published the book "Polyhedron Models for the Classroom" (1973). He has inspired numerous mathematicians and artists around the world. His other three influential books "Polyhedron Models" (1971), "Spherical Models" (1979), and "Dual Models" (1983) have been continuously inspiring the math-art community. Magnus exhibited his work at several Bridges Conferences and Joint Mathematics Meetings.

On October 18, 2017, Bridges community mourned the loss of John Arden Hiigli (1943-2017), a friend and a collaborator. John was a painter and teacher. As an artist and thinker, he was inspired by the oeuvre of Richard Buckminster Fuller, whom he first met in 1970. John's artworks (Fig. 11) have contributed to Fuller's explorations of the geometry of space in a unique way and brought synergetics in art onto a new level. As a teacher, he was a specialist of children's art and curated 


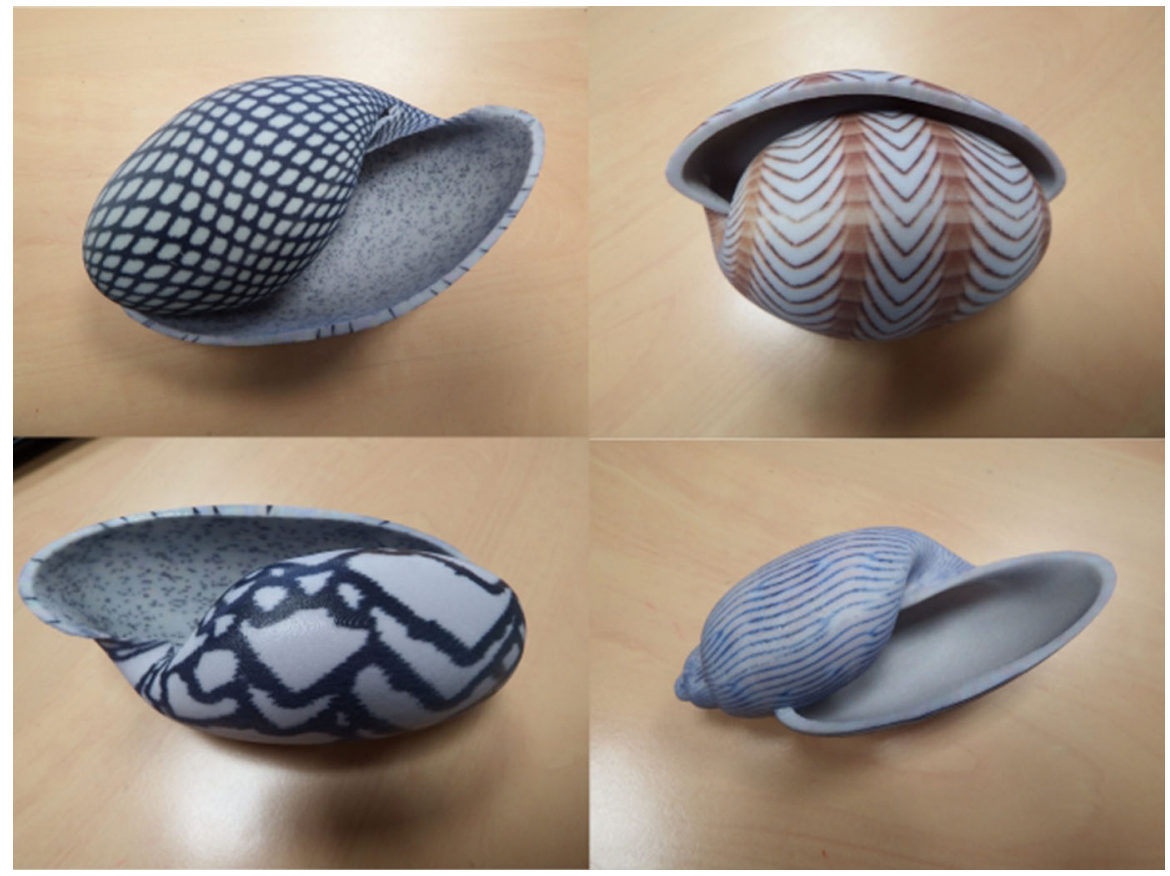

Fig. 8 "Seashells from The Virtual Shore" by Francesco de Comité, Winner of Most Innovative Mathematical Art, Bridges 2017
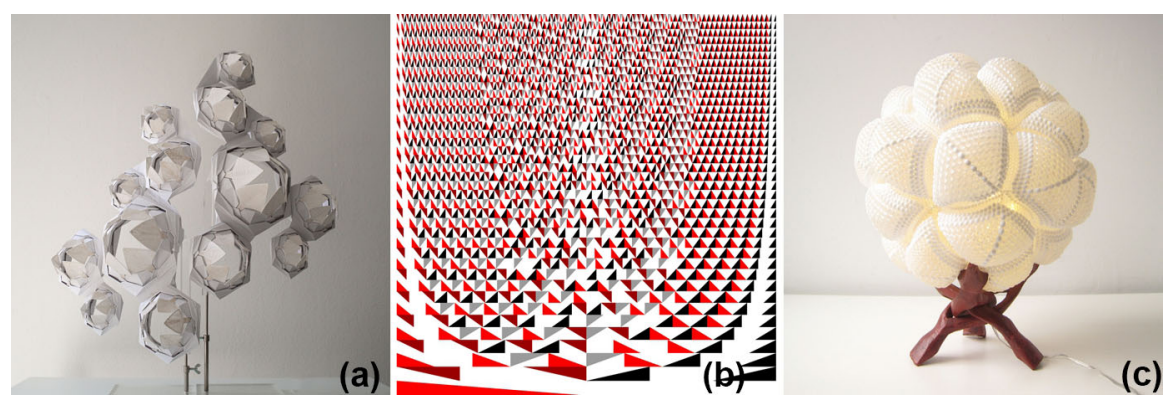

Fig. 9 a "A02_3DP Hygroscopic Programmable Aperture" by David Correa and Achim Menges (Left); b "Interference Pattern of Quantum Random Walk" by Laura De Decker and Raymond Laflamme (Center); c "White II-Light Fixture" by Sharl G. Smith (Right), Bridges 2017

Bridge's Children Art Exhibition together with Kristóf Fenyvesi between 2012 and 2017 (John Hiigli memorial 2017).

Katie McCallum and Robert Fathauer served as co-curators at the Bridges 2017 art exhibition. The 2017 short film festival was chaired by Bianca Violet from IMAGINARY. Bridges 2017 also marked a first art auction organized by Eve Torrence to establish a fund in the memory of Bridges founder, Reza Sarhangi, in support of future invited memorial lectures and student travel scholarships. 


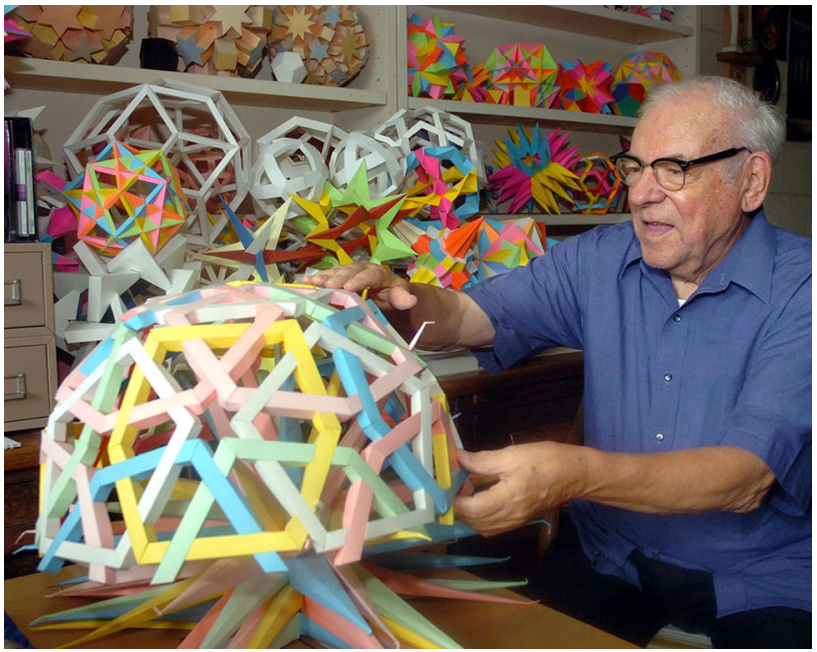

Fig. 10 Magnus Wenninger (1919-2017)

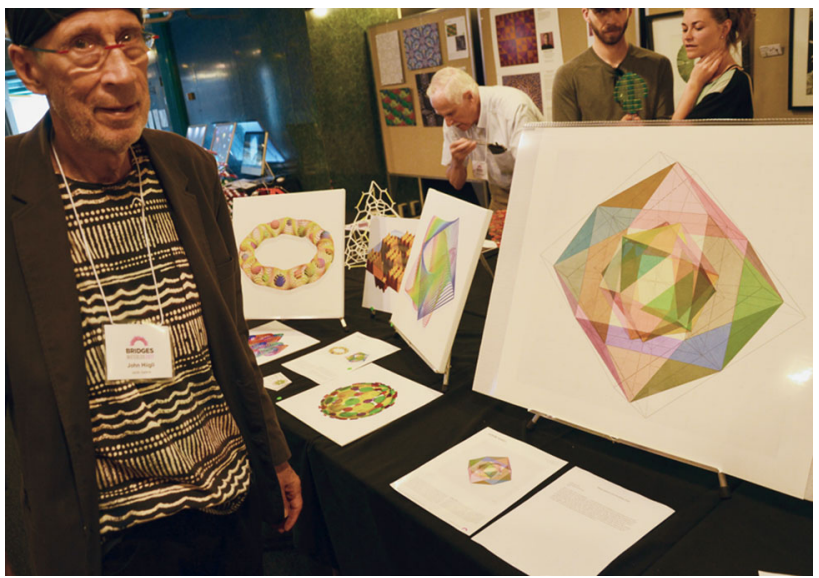

Fig. 11 "Chrome 209" by John Hiigli, Bridges 2017

"Bridges Theater Night" was performed by Peter Taylor and Judy Wearing on a reprise of "Structure: An Allegory", originally performed at the Canadian Mathematics Education Study Group Meeting at Queen's University in 2016. "Formal Music Night" at Bridges 2017 highlighted a vocal ensemble conducted by Mark Vuorinen, a faculty member from the University of Waterloo, with mathematically themed choral music. As each year, Bridges 2017 ended with an "Informal Music Night", hosted by Mike Naylor; this served as a venue for the highly creative interdisciplinary Bridges audience to showcase their own talents.

The diverse mix of scholars with a wide variety of expertise, viewpoints, and the exchange of ideas within the math-art community render the Bridges conference a special place to be each year. Bridges Waterloo 2017 embodied Reza's vision of 


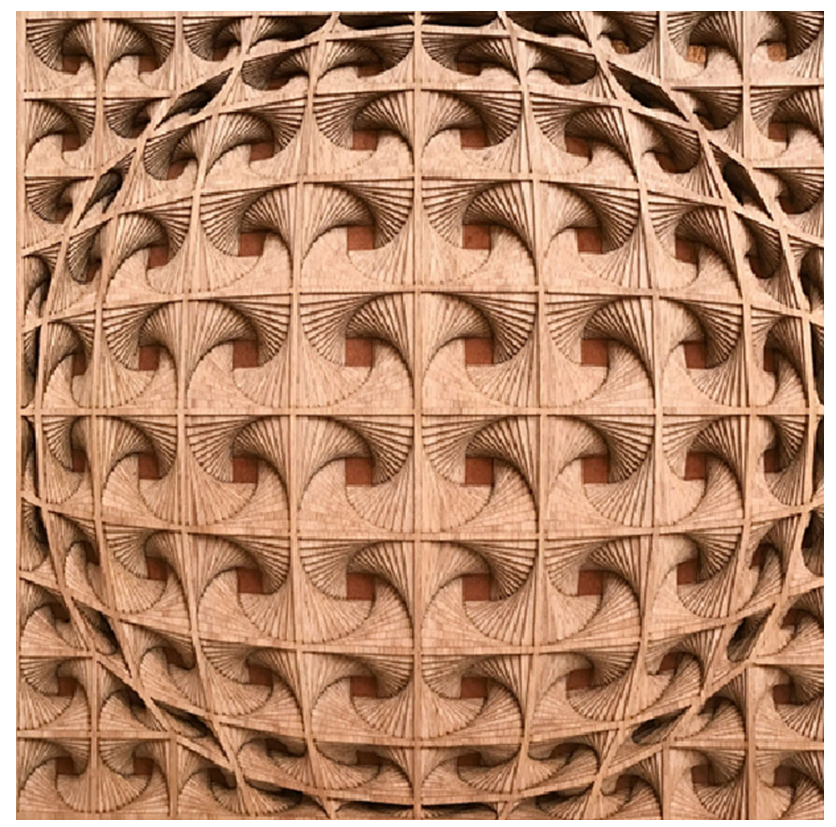

Fig. 12 "Exploding Outward” by Colin Liotta, Winner of Best Craftsmanship, Bridges 2017

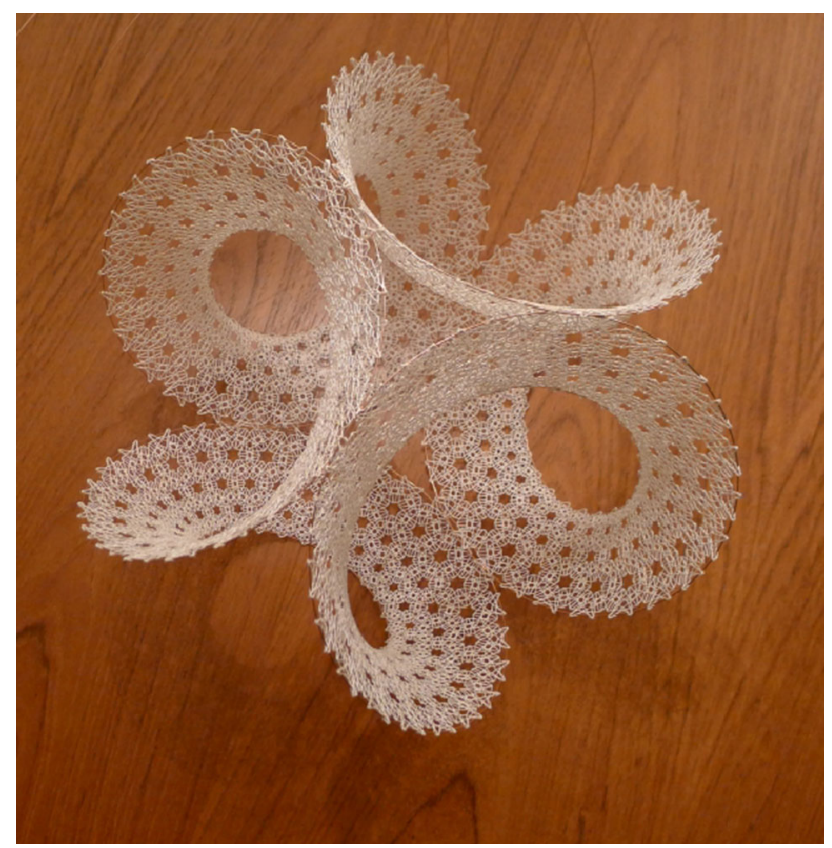

Fig. 13 "Delle Caustiche (Sagittarius Star Cloud)" by Veronika Irvine. Winner of Best in Show, Bridges 2017 
crafting and connecting the field of mathematics and arts that have transformed and touched the lives of many people around the world (Shrestha 2016). The annual Bridges conference will continue to be the reminder of his spirit, and of many others, materializing the exploration and inclusiveness that they valued.

The next Bridges conference will be held at the National Museum of Science and Technology, Stockholm, Sweden, July 25-29, 2018. Check the Bridges organization website (www.bridgesmathart.org) for past and future conference resources.

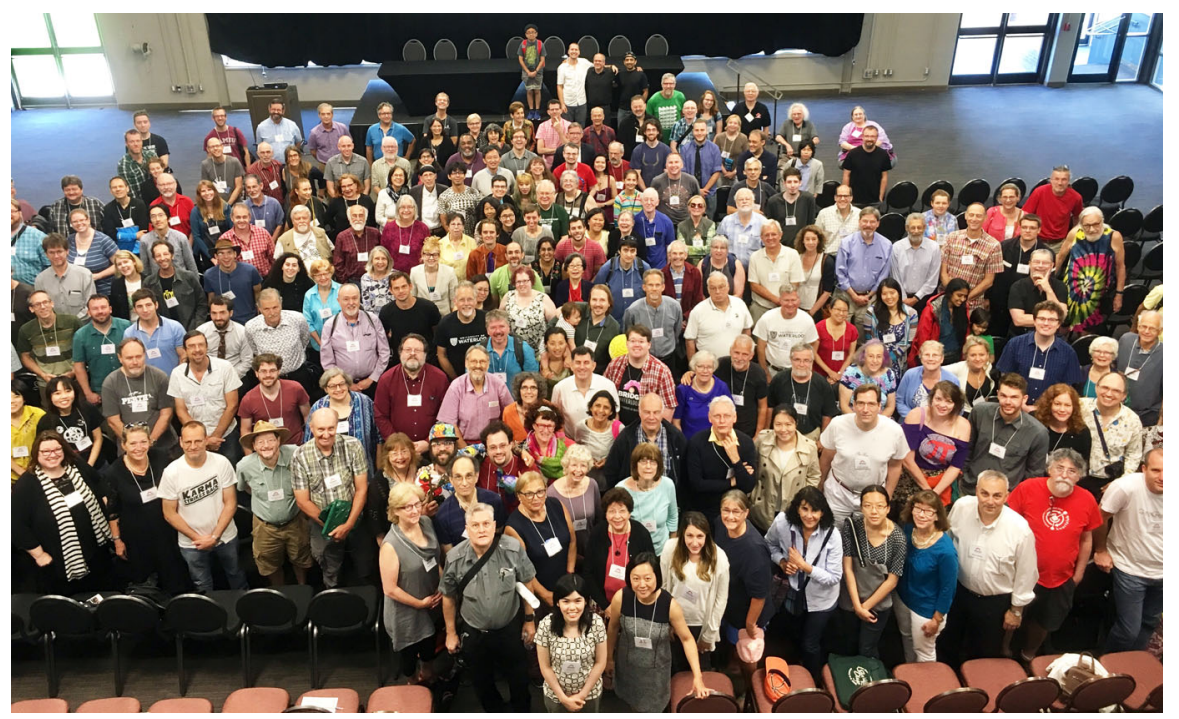

Photo credits

- Group photo is courtesy of Anna Beard.

- Photos not credited otherwise are courtesy of artists from the Bridges website at www.bridgesmathart.org

\section{Appendix}

The 20 years of Bridges Annual Conference Sites

Waterloo, Canada

2015

Jyväskylä, Finland 
Appendix continued

The 20 years of Bridges Annual Conference Sites

\begin{tabular}{ll}
\hline 2010 & Pécs, Hungary \\
2009 & Banff, Canada \\
2008 & Leeuwarden, Netherlands \\
2007 & San Sebastián, Spain \\
2006 & London, England \\
2005 & Banff, Canada \\
2004 & Winfield, Kansas \\
2003 & Granada, Spain \\
2002 & Towson, Maryland \\
2001 & Winfield, Kansas \\
2000 & Winfield, Kansas \\
1999 & Winfield, Kansas \\
1998 & Winfield, Kansas \\
\hline
\end{tabular}

\section{References}

John Hiigli memorial page (2017). https://www.elmenymuhely.hu/farewell-to-john-hiigli-our-mentorand-friend/?lang=en

Kristóf Fenyvesi (2016): Bridges: A world community for mathematical art. The mathematical intelligencer, ISSN: 0343-6993 (print version) ISSN: 1866-7414 (electronic version) The final publication is available at Springer via http://link.springer.com/article/10.1007/s00283-016-9630-9

Reza Sarhangi memorial page (2016). http://bridgesmathart.org/reza-sarhangi/

Sujan Shrestha (2016). In memoriam, Reza Sarhangi. Journal of Mathematics and the Arts10:1-4, p. 1-3

Sujan Shrestha is a faculty member in the division of Science, Information Arts and Technology at the University of Baltimore, Maryland, USA. He teaches game development and media related courses. He currently serves as a board member and the treasurer for the Bridges organization. 